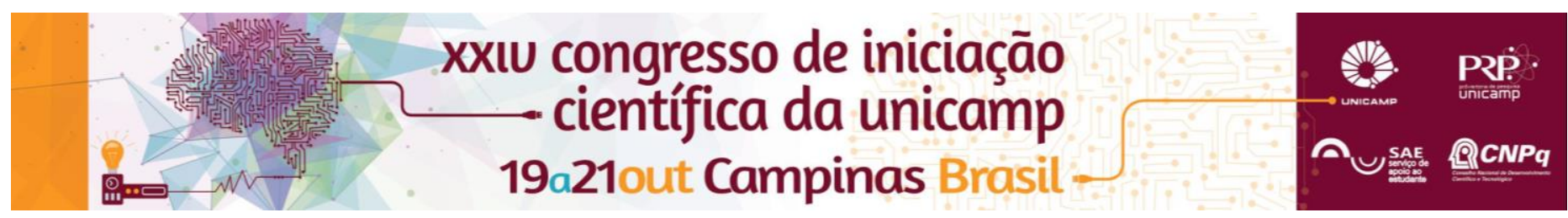

\title{
Otimização de Processo de Determinação de Açúcares e Inibidores em Amostras Hidrolisadas de Microalga por meio de Analise em Cromatografia Líquida de Alta Eficiência
}

Sofia Caroline M. Signorelli, Dra. Telma Teixeira Franco, Dr Fernando Rodrigo Frederico.

\begin{abstract}
Resumo
Esse projeto teve como objetivo a otimização do método de análise de açúcares, inibidores e ácidos orgânicos em HPLC já realizada em nosso laboratório tendo em vista a grande demanda da análise de amostras de microalga com o intuito da produção de bioetanol. Esse método demandou uma série de testes no cromatógrafo, para que obtivéssemos as melhores condições de temperatura interna e externa da coluna, tempo de corrida, volume de injeção, composição e vazão de fase móvel.
\end{abstract}

Palavras-chave

Açúcares, HPLC, Microalga

\section{Introdução}

A biomassa de microalga é fonte de diversos açúcares tais como xilose, glicose, dentre outros muito úteis como substratos para a produção, a partir da biomassa, de diversos produtos químicos de maior valor agregado, como por exemplo, o bioetanol, fonte de energia promissora tendo em vista o intenso desequilíbrio ambiental provocado pelo uso exacerbado de combustíveis fósseis.

No entanto, o tratamento anterior ao processo fermentativo, ao qual a microalga é submetida, gera compostos secundários, como o ácido acético, ácido lático, ácido levulínico e ácido fórmico, além de compostos indesejáveis, gerados pela decomposição de monossacarídeos, que atuam como inibidores do processo fermentativo, tais como o furfural e o 5 Hidroximetil-furfural.

Visando a detecção e avaliação quantitativa e qualitativa dos açúcares presentes em uma amostra de biomassa de microalga hidrolisada, utiliza-se do High performance liquid chromatography (cromatógrafo líquido de alta performance) - HPLC.

No entanto, atualmente, utiliza-se de três corridas no cromatógrafo para a análise destes compostos, uma de açúcares, uma de inibidores e a terceira de ácidos orgânicos. Como o processo é demorado e a necessidade de resultados, de tais análises, é grande, visamos otimizar tal processo, realizando todas as analises em uma corrida única. Desta forma, é necessária uma coluna adequada e condições ideias de temperatura interna e externa da coluna, pressão da coluna, vazão, volume de injeção, tempo de corrida e fase móvel adequada para que obtenhamos a detecção de todos os compostos, de uma única vez, com uma separação de picos adequada para a posterior análise quantitativa e qualitativa.

\section{Resultados e Discussão}

Por meio de diversos testes com várias combinações de colunas, temperaturas, vazões de fase móvel e volume de injeção concluiu-se que as condições mais adequadas para a realização da corrida desejada, com açúcares, inibidores e ácidos orgânicos, seriam:
Tabela 1. Condições Adequadas para a corrida no HPLC

\begin{tabular}{|l|l|}
\hline Coluna & $\mathrm{SH} 1011$ \\
\hline Temperatura Externa: & $70^{\circ} \mathrm{C}$ \\
\hline Temperatura Interna: & $40^{\circ} \mathrm{C}$ \\
\hline Volume de Injeção & $2 \mu \mathrm{L}$ \\
\hline Fase Móvel & Ácido Sulfúrico $0,01 \mathrm{~N}$ \\
\hline Vazão de Fase Móvel & $0,8 \mathrm{~mL} / \mathrm{min}$ \\
\hline Tempo de Corrida & $45 \mathrm{mim}$ \\
\hline
\end{tabular}

Para a realização dos testes com as amostras reais de microalga, utilizamos da chlorella vulgaris. Visando realizar a corrida no HPLC foi necessário efetuar a quebra da parede celular da microalga, buscando a liberação dos açúcares, inibidores e ácidos orgânicos.

A quebra foi feita por meio da hidrólise ácida em autoclave. Para se obter as condições adequadas para o procedimento, foram feitos alguns testes, baseados na bibliografia[1], obtendo-se as seguintes condições: 0,31 $\mathrm{mL}$ de ácido, 9,69mL de água, $0,60 \mathrm{~g}$ de biomassa seca, tempo no autoclave: $50 \mathrm{mim}$, temperatura do autoclave: $121^{\circ} \mathrm{C}$

A quebra foi realizada com sucesso, o que pode ser confirmado por meio da visualização das células em microscopia.

Após a quebra, as amostras necessitaram ser centrifugadas e filtradas antes da injeção no HPLC.

A amostra de microalga apresentou quantidades significativas de glicose, xilose, HMF e furfural. Por meio do teste de glicose oxidase, confirmamos que a quantidade de glicose detectada por meio do método obtido de analise no HPLC foi coerente com o mostrado no teste de glicose oxidase, o que confirmou a eficiência do método.

\section{Conclusões}

Conclui-se que, por meio de uma corrida apenas, é possível a realização da análise de açúcares, inibidores e ácidos orgânicos de forma satisfatória, desde que se utilizem condições adequadas para tanto.

\section{Agradecimentos}

Agradeço a professora Dra.Telma Franco e ao Dr. Fernando Rodrigo Frederico por toda a ajuda que me proporcionaram neste projeto. 